\title{
UNIVERSITIES TRAILING BEHIND: UNQUESTIONED EPISTEMOLOGICAL FOUNDATIONS CONSTRAINING THE TRANSITION TO ONLINE INSTRUCTIONAL DELIVERY AND \\ LEARNING
}

\author{
R. Dlamini \\ Educational Information and Engineering Technology \\ University of the Witwatersrand \\ Johannesburg, South Africa \\ e-mail: Reuben.Dlamini@wits.ac.za / https://orcid.org/0000-0001-6451-333X
}

\author{
N. Ndzinisa \\ Department of Journalism and Mass Communication \\ University of Eswatini \\ Swaziland \\ e-mail: ntndzinisa@uniswa.sz / https://orcid.org/0000-0002-1092-9564
}

\section{ABSTRACT}

Universities across South Africa have positioned learning management systems (LMS) as central to remote teaching and learning in response to COVID-19. This fundamentally challenges traditional teaching and learning practices where lecturers typically have close personal contact with students. Our argument is underpinned by critical discourse analysis and social constructivist pedagogy to gain deeper insights into the dimensions of LMS pedagogical affordances and the notion of equitable access to tertiary education in the midst of COVID-19 and the subsequent education and economic depression. Conducting a social constructivist pedagogy inspired analytical argumentative evaluation, we interrogate how digital technologies and platforms challenge the status quo and then argue on the systemic deficits of placing LMS at the centre of the transition in the hope of automatically cultivating an equitable learning environment to enable ubiquitous learning. Our analysis highlights potential contradictions in universities' reliance on lecturers' ingenuity without developing enabling structures supporting digital pedagogies at grassroots. This is to ensure inclusivity and avoid creating systemic inequalities that affect individual students' experiences.

Keywords: learning management systems affordances, instructional equity, ubiquitous learning

\section{INTRODUCTION}

Across universities information and communication technology (ICT) has fundamentally changed teaching and learning from lecturers having much personal contact with students to a socially oriented activity. The split between the face-to-face and online approaches, especially 
remote teaching, has divided academic staff due to limited online facilitation competencies among faculty. Yes, rapid advances in ICTs have impacted how we teach, learn and process data, which has forced traditional universities to consider changes in education delivery models. Thus, universities have had to invest heavily in digital technologies to embrace online learning and adapt to the changing landscape. This analysis focuses on the implementation of digital technologies in universities to realize their potential as drivers of digital and transformative pedagogies.

By using critical discourse analysis and social constructivist pedagogy as our lenses, we were able to engage with "emergency remote teaching (ERT)" to further understand the tension between technology, context and pedagogy (Hodges et al. 2020, 1). In our approach we studied LMS research between 2011 and 2020 to understand their affordances. However, despite the many cases that have clearly demonstrated the potential of LMS in transforming teaching and learning and the significant improvement in access to education (Rankine-Venaruzzo, Macnamara and Griffin 2014; Rhode et al. 2017; Sadowski, Stewart and Pediaditis 2018; Li 2019), South Africa has yet to realize its educational potential. Worse yet, many lecturers have not been adequately prepared to transition to ERT and do not have the necessary technological abilities. There is no doubt that LMS could revolutionize education (McCabe and Meuter 2011; Linder, Bruenjes and Smith 2017); however, the South African context is still defined by areas with no or poor connectivity and unstable electricity and the technical abilities of most students.

LMS might be an important educational innovation, but the state must build a sound education environment and stable telecommunications infrastructure to avoid excluding more students. Building capacity among lecturers is also a priority, and will ensure that remote teaching is effective and supported, and in the process, they will have to critically examine their own pedagogical beliefs and adopt more constructivist approaches. Thus, in our analysis ERT must be contextualized instead of being prescribed. The tension between technology, lecturers' epistemological position and the conception of teaching and learning are not compatible with the social constructivist pedagogy. Universities must deal with these tensions so that lecturers move in tandem with ERT and move away from homogeneity tendencies to maximise digital technology affordances. With this background, the critical question addressed in this article is:

- What are the underlying values/principles and affordances of digital learning platforms in emergency remote teaching?

It is within these boundaries that we seek to understand the underlying values and affordances of digital learning platforms in ERT. Hence, the primary objective of this article is to present 
an argument on the systemic deficits in the integration of digital platforms into teaching and learning, especially the use of LMS, with the expectation for learning to occur. Finally, we argue that the use of LMS is more than uploading digital learning resources, because this could create systemic inequalities that affect individual students' experiences.

\section{Safe learning ecology}

After the World Health Organisation (WHO) declared the COVID-19 outbreak a global pandemic (WHO 2020), governments implemented strict protocols, such as complete lockdowns, to slow its spread (Bozkurt and Sharma, 2020). According to Bozkurt and Sharma $(2020, i)$, the strict protocols that accompanied complete lockdowns involved the total shut down of buildings, including schools, universities and many other educational institutions. Therefore, the purpose of this argument was to advance the discourse on equitable access to tertiary education in the midst of global challenges such as COVID-19 and the subsequent education system and economic depression. In response to strict COVID-19 social distancing regulations, universities cancelled all face-to-face classes and transitioned to online digital learning platforms such as learning management systems (LMS). Toland et al. $(2014,222)$ define an LMS as "web-based systems that use synchronous and asynchronous technologies for the purpose of delivering educational content and facilitating communication between course participants". It has "become the most prominent and promising educational innovation" to mitigate the risk of losing an academic year because of the COVID-19 pandemic (Yu, Sun and Chang 2010, 332). In an effort to curb the viral outbreak, universities put ERT into practice to sustain the academic year.

With South African universities replacing face-to-face teaching and implementing the ERT approach, LMS became central to the implementation as they allow students to participate in virtual communities and allow students the opportunity to take ownership of their own learning in ways not constrained by time and space. Globally, universities institutionalized digital technologies to enable learning beyond the walls of the classroom through the use of LMS. However, the speed to make the transition was "unprecedented and staggering" and lecturers having to "improvise quick solutions in less-than-ideal circumstances" (Hodges et al. 2020, 2).

While LMS provide an array of powerful functional features such as forums, resources, lessons, tests and quizzes, dropboxes, announcements, assignments and gradebooks, lecturers need to be "fluent users of technology; creative and collaborative problem solvers; and adaptive, socially aware experts throughout their careers" (U.S. Department of Education Office of Educational Technology (OET) 2016, 34). Yes, these features have the potential to 
revolutionize class administration, assessments, communication and the uploading of content materials (McCabe and Meuter 2011; Linder et al. 2017), however a systematic approach informed by instructional design principles must be central as it has impact on the quality of the instruction.

\section{A rationale for digital learning platforms as pedagogical tools}

The ability to learn through dialogue and interaction (Vygotsky 1978a) is enabled through the digital learning platforms or LMS. Technology-enhanced teaching and learning offers great potential for social constructivist pedagogy and learning, complementing the efforts of universities to rescue the academic year (Wang 2014; Chandler and Teckchandani 2015; Yim and Warschauer 2017). However, in the "rush to implement emergency remote teaching" (Bozkurt and Sharma 2020, iii) instructional design principles were absent. Yet, leveraging the technologies in ERT demands appropriate scaffolding and clear guidance, especially in the absence of instructional design principles. In most cases the uploading of content without clear pedagogical guidelines can be overwhelming and frustrating for students. Thus, in order to enjoy the benefits of digital learning platforms, the shift in pedagogy, especially practices that promote homogeneity, must be transformed.

It is no doubt that LMS are enablers with powerful features that can supplement traditional classroom instruction and allow ubiquitous learning. LMS provide "user-friendly platforms that saved instructors time by sparing them from the task of learning programming languages and setting up the programs" (Yu et al. 2010, 333). Linder et al. $(2017,27)$ define LMS as "a software system that offers an organizational structure for a range of course tools to be used by both groups and individuals online". McCabe and Meuter $(2011,150)$ define LMS as "an integrated set of web-based tools to help facilitate course administration and delivery". In summary, LMS facilitate online learning, instructional delivery and self-regulated learning and allows flexible access to assignments and management of courses.

Their profound impact in higher education is well documented and they have been used to connect geographically distributed students in various communities (Toland et al. 2014; Milliner and Cote 2018). As a web-based system, LMS include a course management function that allows lecturers to share instructional resources and learning strategies (Toland et al. 2014). The intuitive usability of the system is critical to the adoption of LMS (West, Waddoups and Graham 2007), and there have been calls for LMS to be more agile to support emerging instructional techniques, personalized learning and flexible learning experiences (Rhode et al. 2017; Li 2019). LMS include a suite of integrated tools that enable communication, assessment, collaboration, tracking learner progress, and reports on students' performance and participation 
(Linder et al. 2017). LMS also extend access to education and instructional delivery and enable learning beyond universities' physical boundaries. All the documented LMS affordances make lecturers instrumental in the successful implementation of LMS, especially the development of LMS pedagogy.

\section{Critical discourse analysis and social constructivist pedagogy as our lens}

To develop deeper insights on digital platforms' impact on pedagogical activities that required universities to undertake massive re-organization and rethink pedagogies, we adopted critical discourse analysis and social constructivist pedagogy as our lenses. Both theories contribute equally to a methodological synergy as we develop an understanding of the systemic deficits of the abrupt implementation of ERT. Critical discourse analysis is understood as "a way of doing discourse analysis from a critical perspective, which often focuses on theoretical concepts such as power, ideology and domination" (Baker et al. 2008, 273). In this case the theory provides a powerful lens for systematically engaging with the discourse on ERT to unearth any pedagogic issues or practices that arise because of structural inequalities in our institutions.

Considering that education is a fundamental human right, the invisible structures in institutions of higher learning continue to create barriers to tertiary education and the consequences are dire. Instead of adopting a one-size-fits-all approach, through critical discourse analysis we can engage with structural variables at curriculum level, societal level and institutional level. Thus, there is no way to ignore the incongruence among students' and lecturers' socioeconomic divide if we are to widen participation and promote equitable access to knowledge. Social constructivist pedagogy emphasizes the social contexts of learning where students actively construct knowledge and understanding (Vygotsky 1978b). However, to avoid epistemic injustice lecturers must be properly trained in order to present content in multimodal forms that take into consideration issues of social and economic context.

\section{Pedagogical issues in Emergency Remote Teaching - ERT}

A challenge in higher education in South Africa is positioning LMS as the central nervous system of the education ecosystem not as a placeholder for supplemental activities in face-toface teaching. The positioning of LMS at the centre of remote teaching creates a tension between pedagogy and technology, and Mentis $(2008,217)$ points out that there is "reciprocal interaction between technology and pedagogical practices". The challenge is that institutional structures are rigid and not welcoming to new pedagogical practices. Institutional structures promote homogeneity and place lecturers at the centre of teaching and learning; however, we should be transitioning "to more open systems where diversity is facilitated and learning is 
located within personalized authentic life-long and life-wide context” (Mentis 2008, 221).

The most common understanding of ERT is that it involves web-based instruction. This approach has been lauded as efficient, flexible and encouraging higher engagement with course material (Frehywot et al. 2013; Protsiv and Atkins 2016), but the biggest challenge was the absent instructional design framework due to the speed of implementation. Noteworthy is that lecturers were thrown into the deep end without proper training on instructional design principles for remote teaching and online learning. This challenge could have negative effects, particularly in the South African context where the lecturer-centred approach still dominates and students "have little control over their access to knowledge" (Laurillard 2010, 1). However, in using a LMS, students are expected to take an active role in their learning, while lecturers are expected to create vibrant learning opportunities that foster participation. This is a daunting task for many academic staff transitioning to ERT given their technological abilities.

Additionally, the challenges of institutionalized digital technologies are a reactive and simplistic approach that does not take into consideration the social and economic realities of our student population. Given the endemic inequality in Africa at large and South Africa in particular, "the speed with which this move to online instruction is expected to happen is unprecedented and staggering" (Hodges et al. 2020, 2). Therefore, a reactive and simplistic approach to the implementation of digital technologies in universities could promote ideals of classism (Dlamini 2018). The transition to the ERT approach and online learning is quite complex and requires long-term planning instead of simply adding technological activities to existing courses (Batchelor 2018). In the current situation, the investment in technology infrastructure has not been matched by professional development activities and development of digital resources to inform new ways of teaching and learning.

Evidently, access and educational needs were the focus when universities adopted LMS to continue with academic activities. Dabbagh and Bannan-Ritland (2005) identify four common features across LMS: Content creation, communication, administration and assessment. The adoption of LMS as the core technology during the time of crisis represents a fundamental change to teaching and learning to cultivate an equitable learning environment that enables ubiquitous learning. Computerising instructional delivery and learning meant that structure and support were critical issues universities had to address to ensure students' success in the context of widening participation into tertiary education (Rankine-Venaruzzo et al. 2014; Sadowski et al. 2018).

Table 1 illustrates the power of LMS to support inclusive pedagogies to encompass various student attributes. 
Table 1: LMS affordances in remote teaching and online learning

\begin{tabular}{|c|c|c|}
\hline Characteristics of LMS & Features & Pedagogical Approach \\
\hline \multirow[b]{2}{*}{ Communication } & Announcement & Asynchronous communication \\
\hline & Forums & $\begin{array}{l}\text { Asynchronous communication } \\
\text { Collaborative learning } \\
\text { Reciprocal learning } \\
\text { Multiple forms of support } \\
\text { Interactivity and sharing ideas } \\
\text { Continuous and timely feedback }\end{array}$ \\
\hline \multirow[t]{2}{*}{ Content Creation } & Resources & $\begin{array}{l}\text { Multimodal content creation } \\
\text { Organize content into folders and subfolders } \\
\text { Self-regulated learning } \\
\text { Hosting hyperlinks pointing to essential websites }\end{array}$ \\
\hline & Lessons & Multimodal content creation \\
\hline \multirow{4}{*}{ Assessment } & Test and Quizzes & $\begin{array}{l}\text { Assessments is not an episode but an ongoing } \\
\text { series of linked activities undertaken by students } \\
\text { over time } \\
\text { Randomization of questions in the form of multiple } \\
\text { choice questions, fill in the blank(s), and true or } \\
\text { false. }\end{array}$ \\
\hline & Assignment & $\begin{array}{l}\text { Lecturers create and manage assignments } \\
\text { Continuous and timely feedback }\end{array}$ \\
\hline & Dropbox & $\begin{array}{l}\text { Students submit assignments for grading and } \\
\text { feedback }\end{array}$ \\
\hline & Turnitin & $\begin{array}{l}\text { Ability to prevent plagiarism by checking } \\
\text { documents for originality } \\
\text { Plagiarism detection promotes quality academic } \\
\text { writing }\end{array}$ \\
\hline \multirow[t]{2}{*}{ Administration } & Grouping & $\begin{array}{l}\text { Creating small groups and assigning tutors to } \\
\text { provide more personalized learning and give } \\
\text { attention to individual students } \\
\text { Continuous and timely feedback }\end{array}$ \\
\hline & Gradebook & Monitoring of students' progress toward goals \\
\hline
\end{tabular}

LMS features unlock learning in many ways, including access to distributed knowledge, asynchronous and synchronous activities, and provide richer learning experiences for students (Rankine-Venaruzzo et al. 2014; Rhode et al. 2017; Li 2019). Table 1 shows the importance of embracing disruptive pedagogies that offer rich opportunities for collaboration, interactivity, and socio-experiential learning (Lee and McLoughlin 2008). However, students have to deal with the challenge of balancing their studies and life when they work from home, and lecturers have the challenge to maximise the pedagogical affordances of LMS. Maximising the pedagogical affordances of LMS takes planning, mapping and aligning outcomes with course objectives. In the planning process academics need to think about the technology, pedagogy and the context and ask the following questions:

- What are the learning objectives and practices needed for students to successfully achieve the outcomes of the lesson?

- What content modalities are available through technology to facilitate learning?

- What technological affordances could effectively engage students in their cognitive 
development process to achieve the learning outcomes?

- What digital teaching and learning resources are readily available to adapt to support or facilitate online teaching and learning?

It is important for universities and especially lecturers to ensure continuity during this pandemic and to consider this a unique opportunity to develop new pedagogical approaches based on the instructional design principles for online teaching and learning. The challenge is to ensure that all students have access to learning opportunities, regardless of their socioeconomic status. Unfortunately, the current state of affairs "reflect racial, economic and resource differences [in] a situation that has exposed glaring inequities" (Feldman 2020, 44). Therefore, we are saying that removing students' concerns from the equation is problematic and disregards the realities of our society.

\section{Pitfalls to successful multimodal teaching and learning to achieve epistemic justice}

In South Africa, major challenges within universities are academics' negative perceptions of online learning platforms, lecturers' access to computing devices and the associated support and training requirements, as well as students' access to computing devices and data. Using technology to intensify teaching and curriculum coverage is a step in the right direction; however, the situation must be socially just to ensure fair access and distribution of learning resources across communities, especially among historically disadvantaged groups. Not paying careful attention to the context of students and the basic capacity-related characteristics inherent to the integration of ICT could result in widening the gap between the "haves" and "haves not". The "haves" will continue to have access to tertiary education, resulting in economic insecurity and social deprivation to the "haves not".

The challenge is to transform social structures that could deepen inequalities and restrict access to higher education (Dlamini 2018). Instead of rationalizing education, the unfathomable challenges must be understood so that universities are "responsive to the goals of equity, efficiency, democratic participation and development" (Habib 2016, 36). Academic staff's "reluctance to abandon their existing pedagogy" and "concerns about disruption to established pedagogical approach" are major challenges (Hennessy, Ruthven and Brindley 2005, 159). Yet, the objective should be to support instead of disrupt students in their exploration journey.

There is absolute value in universities understanding both lecturers' and students' concerns and then developing the required support structures. Universities should strive to institutionalize approaches to improve policy coherence and back it with enabling ICT 
infrastructure to enable the pedagogical integration of ICT, instead of having ICT as an add-on. Yes, digital technologies such as LMS are enablers with powerful features and can supplement traditional classroom instruction, but despite the many LMS affordances, adopting it largely depends on the lecturers' abilities, attitude and confidence in the use of digital learning platforms.

According to $\mathrm{Yu}$ et al. (2010) 'instructors' commitment and enthusiasm in using technology could exert a positive influence not only in their teaching efficiency, but also on their students' satisfaction in working with Course Management Systems, and could further alleviate learners' learning anxiety" (Yu et al. 333). Thus, the conceptual gap of online instructional delivery and learning calls for research on LMS affordances during such a crisis. Following the COVID-19 outbreak in early 2020 and its classification as a global pandemic by the WHO (WHO 2020), universities began working on plans to save the academic year after the South African government instituted a complete lockdown to curb the spread of the virus (CNBC Africa, 2020). It was important to salvage the academic year as losing an academic year could widen tertiary education access inequalities and hurt vulnerable and disadvantaged students.

This meant universities had to transfer their teaching and learning activities to digital online platforms. As universities began to ramp up LMS, the reality that many students reside in rural areas where connectivity is a problem began to surface as part of discussions between Students Representative Councils and universities' Senior Executive Teams. Some of South Africa's blue chip institutions (University of Cape Town, University of the Witwatersrand, University of KwaZulu-Natal, University of Pretoria, University of Stellenbosch) began putting digital infrastructure in place and channelling lecturers to LMS to facilitate online learning. On April 20, 2020, universities resumed their academic year on digital online platforms backed by deals secured with telecom companies to provide free data to all students from April 20, 2020, and zero-rated websites to support remote teaching and online learning. These institutions went as far as securing laptops to loan to students to ensure they can access the online learning platforms.

What was not clear or remained unresolved was the fair and equitable access to online platforms during the Covid-19 pandemic, especially in rural and remote area. Issues of connectivity in rural and poverty stricken communities remain unresolved. Hence, the main issues faced by students and lecturers in rural and remote areas is connectivity and stable electricity. That scenario meant that students began learning online without proper preparation and their access to digital learning resources is minimal affecting them from achieving the learning goals. 


\section{DISCUSSION}

Our analysis makes it clear that the massive re-organizing and rethinking of pedagogies acknowledge that ICT has an important role to play, but it is still treated as a novel outsider in the classroom. However, the focus should be equitable access and transforming the learning context before dangling ubiquitous learning, especially in the ever growing diversity of knowledge. The speed with which ERT has been implemented influences the application of instructional design principles; this will have long-term effects by widening the gap of access to tertiary education because lecturers had to "improvise quick solutions in less-than-ideal circumstances" (Hodges et al. 2020, 2). Given that there are huge gaps in current pedagogical approaches, we should reconsider our stance of placing our hope on digital learning platforms without the development of online teaching and learning architecture.

ERT requires the adoption of a new pedagogy design that lecturers and students had not been fully prepared for prior to the pandemic. While numerous South African universities have been slowly transitioning to online learning through the blended learning approach, some members of faculty and students may have not been fully utilising LMS. However, the sudden total shutdown of universities because of the COVID-19 pandemic has demanded a swift change from face-to-face learning to online learning without giving students and faculty time to adapt to the new environment. Online instruction requires a change in delivery modalities, and by extension, adjusted formative and summative assessments to evaluate students' understanding of course content. However, challenges arise when lecturers attempt to tweak assessment techniques used in traditional face-to-face classrooms to fit online instruction (Vonderwell, Liang and Alderman 2007).

Research also shows that lecturers have a tendency to use LMS as a repository for course content, such as lecture notes, and as an administration tool rather than a teaching tool (Mlitwa and Van Belle 2011). However, online learning platforms are "dynamic tools to facilitate the process of learning, such as synchronous and asynchronous discussion groups" (Chaubey and Bhattacharya 2015, 160). Lecturers' narrow perception of LMS and poor adherence to instructional design principles place them at the centre of teaching and learning, which negatively impacts LMS affordances in ERT. Consequently, academics are increasingly frustrated by their attempts to emulate face-to-face teaching in an online environment. Embracing social constructivist pedagogies that acknowledge that learning is an "active rather than passive process" (Anderson and Dron 2011, 85) is central to successfully implementing online learning and remote teaching. This will allow academics to focus on students' creativity and diversity in the construction of knowledge and encourage cognitive development. 
Further, placing LMS at the heart of teaching and learning can exacerbate entrenched inequalities and injustices prevalent in the South African context in general and in the education system in particular. While some South African universities have attempted to bridge these inequalities by providing technological tools and data, challenges remain in home learning environments. Thus, an over-reliance on digital learning platforms may mean that students get access to course materials, but little learning takes place.

\section{CONCLUSION}

This analysis highlights potential contradictions in universities' reliance on lecturers' ingenuity without developing enabling structures to support digital pedagogies at grassroots. The reality is that most lecturers have not been adequately prepared to provide ERT and this has serious implications for systemic inequalities and epistemic injustice. Universities must grapple with issues of invisible structures and gaps that exist in the South African context to ensure that equity and inclusivity in ERT is a reality. The COVID-19 epidemic has made the inequalities that exist in our institutions of higher learning visible. Historically black universities are already left behind, while blue chip universities thrive in the new terrain of online teaching and learning. Clearly using technology to intensify teaching and curriculum coverage is a step in the right direction, but the situation must be socially just to ensure fair access and distribution of learning resources across communities, especially among historically disadvantaged groups. There must be structures that link pedagogy, technology and context to avoid creating systemic inequalities that affect individual students' experiences. Clearly, ERT is at odds with current institutional structures, society and students' realities.

\section{REFERENCES}

Anderson, T. and J. Dron. 2011. Three generations of distance education pedagogy. The International Review of Research in Open and Distributed Learning 12(3): 80-97.

Baker, P., C. Gabrielatos, M. Khosravinik, M. Krzyżanowski, T. McEnery and R. Wodak. 2008. A useful methodological synergy? Combining critical discourse analysis and corpus linguistics to examine discourses of refugees and asylum seekers in the UK Press. Discourse \& Society 19(3): 273-306.

Batchelor, J. 2018. Learning design principles to support communities of practice in a blended learning programme. In 9th Annual UNISA ISTE Conference on Mathematics, Science and Technology Education: 315.

Bozkurt, A. and R. C. Sharma. 2020. Emergency remote teaching in a time of global crisis due to Coronavirus pandemic. Asian Journal of Distance Education 15(1).

Chandler, J. D. and A. Teckchandani. 2015. Using social constructivist pedagogy to implement liberal learning in business education. Decision Sciences Journal of Innovative Education 13(3): 327348.

Chaubey, A. and B. Bhattacharya. 2015. Learning management system in higher education. 
International Journal of Science Technology \& Engineering 2(3): 158-162.

CNBC Africa. 2020. Breaking: Nationwide lockdown announced in South Africa. https://www. cnbcafrica.com/news/2020/03/23/breaking-nationwide-lockdown-announced-in-south-africa/ (Accessed 18 May 2020).

Dabbagh, N. and B. Bannan-Ritland. 2005. Online learning: Concepts, strategies, and applications. Upper Saddle River: Pearson Education.

Dlamini, R. 2018. Corporatisation of universities deepens inequalities by ignoring social injustices and restricting access to higher education. South African Journal of Higher Education 32(5): 54-65.

Feldman, J. 2020. To grade or not to grade? How districts can enact fair and equitable grading policies during the coronavirus closures. Educational Leadership Special Report https://filecabinetdublin. eschoolview.com/6D88CF03-93EE-4E59-B267-B73AA2456ED7/ToGradeorNottoGrade article.pdf (Accessed 18 May 2020).

Frehywot, S., Y. Vovides, Z. Talib, N. Mikhail, H. Ross, H. Wohltjen, S. Bedada, K. Korhumel, A. K. Koumare and J. Scott. 2013. E-learning in medical education in resource constrained low-and middle-income countries. Human Resources for Health 11(1): 4.

Habib, A. 2016. Transcending the past and reimagining the future of the South African university. Journal of Southern African Studies 42(1): 35-48.

Hennessy, S., K. Ruthven and S. Brindley. 2005. Teacher perspectives on integrating ICT into subject teaching: Commitment, constraints, caution, and change. Journal of Curriculum Studies 37(2): $155-192$.

Hodges, C., S. Moore, B. Lockee, T. Trust and A. Bond. 2020. The difference between emergency remote teaching and online learning. EDUCAUSE Review. https://er.educause.edu/articles/ 2020/3/the-difference-between-emergency-remote-teachingand-online-learning.

Laurillard, D. 2010. Rethinking university teaching: A framework for the effective use of learning technologies. TechTrends 69.

Lee, M. J. W. and C. McLoughlin. 2008. Harnessing the affordances of Web 2.0 and social software tools: Can we finally make "student-centered" learning a reality? In Proceedings of ED-MEDIA 2008 - World Conference on Educational Multimedia, Hypermedia \& Telecommunications, edited by J. Luca and E. Weippl, 3825-3834. Vienna, Austria: Association for the Advancement of Computing in Education (AACE). https://www.learntechlib.org/p/28915 (Accessed 18 April 2020).

Li, Y. 2019. University teachers' pedagogical work with canvas an exploration of teachers' conceptions, design work and experiences with an LMS. Master's thesis.

Linder, K. E., L. S. Bruenjes and S. A. Smith. 2017. Hybrid platforms, tools, and resources. New Directions for Teaching and Learning 149: 27-36.

McCabe, D. B. and M. L. Meuter. 2011. A student view of technology in the classroom: Does it enhance the seven principles of good practice in undergraduate education? Journal of Marketing Education 33(2): 149-159.

Mentis, M. 2008. Navigating the e-Learning terrain: Aligning technology, pedagogy and context. Electronic Journal of e-Learning 6(3): 217-226.

Milliner, B. and T. J. Cote. 2018. Faculty adoption, application, and perceptions of a CMS in a university English language program. In Handbook of research on integrating technology into contemporary language learning and teaching, 161-175. IGI Global.

Mlitwa, N. and J. P. Van Belle. 2011. Mediators for lecturer perspectives on learning management systems at universities in the Western Cape, South Africa. In PACIS, 135.

Protsiv, M., S. Atkins and ARCADE Consortium. 2016. The experiences of lecturers in African, Asian and European universities in preparing and delivering blended health research methods courses: A qualitative study. Global Health Action 9(1): 28149.

Rankine-Venaruzzo, L., D. Macnamara and T. Griffin. 2014. Changing the face of learning @ UWS. In 
Rhetoric and reality: Critical perspectives on educational technology. Proceedings Ascilite Dunedin, 58-68.

Rhode, J., S. Richter, P. Gowen, T. Miller and C. Wills. 2017. Understanding faculty use of the learning management system. Online Learning 21(3): 68-86.

Sadowski, C., M. Stewart and M. Pediaditis. 2018. Pathway to success: Using students' insights and perspectives to improve retention and success for university students from low socioeconomic (LSE) backgrounds. International Journal of Inclusive Education 22(2): 158-175.

Toland, S., J. White, D. Mills and D. U. Bolliger. 2014. EFL instructors' perceptions of usefulness and ease of use of the LMS Manaba. JALT CALL Journal 10(3): 221-236.

U.S. Department of Education Office of Educational Technology (OET). 2016. Future ready learning: Reimagining the role of technology in education. 2016 national education technology plan. https://tech.ed.gov/files/2015/12/NETP16.pdf.

Vonderwell, S., X. Liang and K. Alderman. 2007. Asynchronous discussions and assessment in online learning. Journal of Research on Technology in Education 39(3): 309-328.

Vygotsky, L. 1978a. Interaction between learning and development. Readings on the development of children 23(3): 34-41.

Vygotsky, L. S. 1978b. The role of play in development. Mind in Society 5: 92-104.

Wang, Y. C. 2014. Using Wikis to facilitate interaction and collaboration among EFL learners: A social constructivist approach to language teaching. System 42: 383-390.

West, R. E., G. Waddoups and C. R. Graham. 2007. Understanding the experiences of instructors as they adopt a course management system. Educational Technology Research and Development 55(1): $1-26$.

WHO see World Health Organisation.

World Health Organisation. 2020. Coronavirus disease (COVID-19) Pandemic. World health Organization. https://www.who.int/emergencies/diseases/novel-coronavirus-2019

Yim, S. and M. Warschauer. 2017. Web-based collaborative writing in L2 contexts: Methodological insights from text mining. Language Learning \& Technology 21(1): 146-165.

Yu, W. K., Y. C. Sun and Y. J. Chang. 2010. When technology speaks language: An evaluation of course management systems used in a language learning context. ReCALL 22(3): 332-355. 